\title{
DIREITOS HUMANOS, POPULAÇÕES TRADICIONAIS E QUILOMBOLAS E DESENVOLVIMENTO: O CASO DO APROVEITAMENTO HIDRELÉTRICO CASTELHANO
}

HUMAN RIGHTS AND TRADITIONAL QUILOMBOLA POPULATION AND DEVELOPMENT: THE CASE OF HYDROELECTRIC CASTILLIAN

\author{
Matheus Nunes Tajra ${ }^{1}$ \\ Maria Sueli Rodrigues de Sousa ${ }^{2}$ \\ Daniel de Moura Sá Araújo ${ }^{3}$
}

\section{RESUMO}

O presente trabalho discute o tema desenvolvimento relacionado à garantia de direitos humanos de populações tradicionais e quilombolas a partir do relatório parcial do Projeto de Pesquisa e Extensão - Territorialização, desterritorialização e reterritorialização na dinâmica de desenvolvimento no Estado do Piauí, desenvolvido no âmbito do Programa Jovens Talentos Para a Ciência do Ministério da Educação na UFPI. A pesquisa orientou-se pela questão: como garantir o direito ao desenvolvimento combinado com as garantias legais de direitos humanos $e$ fundamentais? A discussão toma como referência o pressuposto de que em Estados constitucionais com fundamento na democracia os direitos humanos e fundamentais estruturam o Estado e que a garantia de direito não autoriza a violação de outro direito (HABERMAS, 2003). Na perspectiva metodológica, foi eleita, no polo epistêmico, a orientação da pesquisa qualitativa, considerando formas diversas de produção de sentido a partir da empiria observada no cotidiano (SPINK, 2010) e o estudo de caso (2004) apropriado teoricamente como hard case (DWORKIN, 2002)

\footnotetext{
${ }^{1}$ Estudante de graduação em Direito da Universidade Federal do Piauí e integrante do Projeto de Pesquisa e Extensão - Territorialização, desterritorialização e reterritorialização na dinâmica de desenvolvimento no Estado do Piauí. Bolsista de iniciação científica do Programa Jovens Talentos Para a Ciência (Capes). E-mail: mat_nunes@hotmail.com

${ }^{2}$ Doutora em Direito, Estado e Constituição - UnB, Mestra em Desenvolvimento e Meio Ambiente PRODEMA - UFPI, Profa Adjunta - UFPI - Departamento de Ciências Jurídicas. E-mail: mariasuelirs@ufpi.edu.br

${ }^{3}$ Estudante de graduação em Direito da Universidade Federal do Piauí e bolsista de iniciação científica do Programa Jovens Talentos Para a Ciência (Capes). E-mail: daniel.ptw@gmail.com
} 
e no polo morfológico a junção do tripé ensino, pesquisa e extensão (SOUSA etall, 2013). Como resultados há a discussão da evidência de violação de direitos humanos e fundamentais de populações tradicionais e quilombolas numa Comunidade Quilombola "Riacho dos Negros", no município de Palmeirais, Estado do Piauí,sob ameaça de desterritorialização compulsória para implantação de um aproveitamento hidrelétrico e a discussão teórica da aparente colisão de direitos fundamentais e as respostas, a única correta ou a melhor resposta, que o sistema do direito pode oferecer diante de um hard case.

Palavras-chave: Aproveitamento Hidrelétrico Castelhano. Comunidades tradicionais e quilombolas. Direitos Humanos.

\section{ABSTRACT}

This paper discusses the theme development related to ensuring the human rights of traditional and Maroon peoplebased in the partial report of the Project for Research and Extension - Territorialization, deterritorialization and reterritorialization in the dynamic of development in the state of Piauí, developed under the Ministry of Education's program Young Talentsto Scienceat UFPI. The research was guided by the question: how to ensure the right to development combined with legal guarantees of fundamental human rights? The discussion takes as reference the assumption that in states with constitutional base in democracy, human and fundamental rights structure the State and that the guarantee of law does not authorize the violation of other rights (HABERMAS, 2003). In methodological perspective, was elected, inepistemic polo,the qualitative research, considering the different ways of producing meaning from the empirical observed in everyday life (SPINK, 2010) and case study (2004) theoretically appropriate as hard case (DWORKIN, 2002) and, in morphological pole, the junction os the tripod teaching, research and extension (Sousa et al, 2013). As a result, there is a discussion about evidences of human and fundamental rights violations of traditional and maroon people in the Marron community of Riacho dos Negros, in the city of Palmeirais, state of Piauí, under threat ofcompulsory dispossession to implement a hydroelectric and the theoretical discussion of apparent collision fundamental rights and the responses, the best answer or the only correct one the system can provide before a hard case. 
Keywords: Castelhano Hydroelectric. Traditional and maroon communities. HumanRights.

\section{CONSIDERAÇÕES INICIAIS}

$\mathrm{Na}$ última década, o Brasil, a partir das políticas de governo, adotou programas e projetos de desenvolvimento com o objetivo anunciado de crescimento econômico e, dentre as metas do desenvolvimento, há a de maior crescimento de regiões pobres do país: norte, nordeste e centro-oeste. O Estado assumiu um papel de indutor do desenvolvimento, cabendo-lhe implantar infraestrutura viária, energética e adotar políticas de incentivo fiscal para atrair o capital privado.

O cenário indicado desenhou-se no Estado do Piauí com a implantação de vias rodoviárias e ferroviária e de matrizes energéticas. Dentre elas, destaca-se a construção de cinco novas barragens no rio Parnaíba para a produção de energia elétrica, o que atende a demanda por energia elétrica e representa impacto ao meio ambiente, fauna e flora regionais, além do impacto no modo de vida da população residente nas áreas a serem inundadas.

O foco deste trabalho recai sobre a Barragem de Castelhano, que atingirá municípios dos estados do Piauí e Maranhão e resultará em desapropriação, indenização ou compra de terras hoje ocupadas por proprietários, pequenos proprietários, minifundistas e posseiros. Contudo, o Estudo de Impacto Ambiental não prevê o local em que serão reassentadas as populações locais que serão atingidas pelo empreendimento. Dentre as áreas previstas como impactadas pelas inundações, há a comunidade de Riacho dos Negros, em Palmeirais (PI), na qual é possível constatar elementos que fundamentam a sua autoidentificação como remanescente de quilombos, conforme será abordado neste trabalho. A mobilização dos moradores dessa comunidade, a luta pela efetivação de seus direitos, a repercussão do tema na mídia e a discussão entre diversos setores da sociedade têm sido acompanhadas pela equipe do Projeto de Pesquisa e Extensão Conhecimentos tradicionais e quilombolas na conservação da biodiversidade piauiense numa perspectiva sócio-jurídica,desde que o projeto foi anunciado pelo governo piauiense. 
Assim, a primeira seção deste artigo apresenta a discussão sobre métodos e técnicas adotadas na pesquisa. Já a segunda seção, dividida em três partes, expõe os resultados e discussão:a princípio, traz as características básicas do projeto da Barragem de Castelhano e as suas consequências para os moradores e para a biodiversidade da área atingida, a serem aprofundadas na sequência. Pretende-se discutir ainda alguns aspectos que embasam a Ação Civil Pública ajuizada pelo Ministério Público Federal com o propósito de impedir os leilões das barragens ao longo do rio Parnaíba. Então, tece considerações acerca das implicações da construção da Barragem de Castelhano para o meio ambiente e para as comunidades por ela atingidas, além de tratar das violações de direitos humanos que seus residentes têm sistematicamente sofrido.

Essa discussão tem como base uma série de informações colhidas em visita ao local realizada em março de 2013 pela equipe do Projeto de Pesquisa e Extensão supracitado, vinculado ao Departamento de Ciências Jurídicas da Universidade Federal do Piauí. Naquela oportunidade, além de conhecer melhor a extensão das terras a ser inundada, foi possível ter acesso a documentos e mapas cedidos pela Associação de Moradores e, o mais importante, ter contato direto com pessoas cujas famílias são residentes da área há várias gerações e colher entrevistas que permitiram identificar diversos conhecimentos tradicionais e o modo diferenciado de lidar com a biodiversidade local que isso implica.

As informações obtidas permitem descrever a Comunidade Riacho dos Negros como comunidade tradicional e quilombola, com proteção ampla e específica na CF/88, em convenções internacionais e legislação ordinária e o empreendimento é apresentado sob o fundamento de supremacia do interesse público. Dessa forma, pode-se afirmar que o cerne da discussão neste trabalho é questionar até que ponto o argumento de supremacia do interesse público pode justificar, por exemplo, a violação de normas adotadas pelo Brasil que exigem consulta prévia a comunidades tradicionais e quilombolas, como a Convenção 169 da OIT. Por fim, ao promover o diálogo entre as teorias de Beck e Habermas no estudo do caso, pretende-se demonstrar a relevância da ideia de risco no campo do Direito Ambiental. Isso implica a demanda por mecanismos eficazes para lidar com esse risco que permeia 
a sociedade que, aliados ao Direito, reconheçam e respeitem os direitos das minorias e possam assim evitar conflitos.

\section{MATERIAIS E MÉTODOS}

A discussão sobre materiais e métodos se dará na observância a três aspectos: epistemológico; teórico e morfológico/operacional. No quesito epistemologia, considerou-se as ciências sociais como questionadoras do monismo científico que unificou todas as ciências na produção de sentido a partir da realidade pelas regularidades, eventos contáveis e estatísticos, sendo as ciências sociais as produtoras do dualismo entre estas e as ciências da natureza e que a crise da modernidade colocou por terra ou tomou-o como superado, o que segundo Habermas (2009) atrofiou a diferença. Considerando a existência da diferença, o presente trabalho não intencionou produzir sentido a partir das regularidades que permitem fazer declaração de universalização do fenômeno, mas apenas estudar caso (GOLDEMBERG, 2004) para (re)visitar processos de interpretação de casos difíceis [hards cases] (DWORKIN, 2003), aqueles que dividem a sociedade por envolver princípios constitucionais que no caso empírico parecem colidirem.

A referida orientação epistemológica fundamenta as escolhas no polo morfotécnico da pesquisa: pesquisa qualitativa, considerando que as informações quantitativa e qualitativa são diferentes, podendo até ser complementares em determinados aspectos, mas nunca para uma afirmar ou negar as conclusões da outra, considerando que são diferentes olhares com objetivo diverso.

Goldemberg (2004), ao fazer um levantamento da relação pesquisa qualitativa e quantitativa, refere que, para Dilthey, os fatos sociais não são passíveis de quantificação por terem sentido próprio diferente dos demais, o que exige que cada caso concreto seja compreendido em sua singularidade e considera que as Ciências Sociais devem se preocupar com a compreensão de casos particulares e não com formulação de leis gerais enquanto que às Ciências da Natureza cabe buscar a generalização e a descoberta de regularidades, às Ciências Sociais visa compreender de modo interpretativo as experiências dos indivíduos. 
No polo teórico da metodologia, adotamos a perspectiva de que o empírico na ciência jurídica encontra-se no próprio campo das ciências jurídicas, portanto numa visão oposta à tradição que exclui a pesquisa empírica da ciência jurídica, tomandoa como: antropologia, sociologia, psicologia, economia, ciência políticas, dentre outras.

Referente ao polo técnico e morfológico cabe citar as técnicas adotadas: levantamento de informações: EIA/RIMA, Ação Civil Pública, visita à comunidade, observação empírica com registro em diário de campo, documentos da associação de moradores da comunidade, dados sobre o objeto para a análise quantitativa, e análise documental com produção de diário de campo, mapas ${ }^{4}$ analíticos com as categorias (SPINK, 2010), visando preservar o contexto interativo, considerando que os mapas são instrumentos de visualização do processo de interação, que remetemaum estilo de exploração de territórios que tem como pressuposto a existência objetiva de terrenos cujas características podem ser reproduzidas em signos, imagens, textos. Dos mapas analíticos foram produzidas as narrativas sobre o objeto estudo e os textos analíticos que seguem abaixo.

\section{RESULTADOS E DISCUSSÃO}

\subsection{AHE Castelhano: descrição do caso}

Justificada com a discursividade de necessidades energéticas da região, a barragem de Castelhano é um empreendimento que integra o conjunto de cinco barragens do Projeto Parnaíba a serem construídas pelo Programa de Aceleração do Crescimento (PAC) e propostas pelo consórcio das empresas CHESF, Construtora Queiroz Galvão, CNEC Engenharia S.A. e ENERGIMP S.A. De acordo com os Estudos e o Relatório de Impacto Ambiental (EIA/RIMA), elaborados para o consórcio, a referida barragem, a ser instalada na bacia hidrográfica do rio Parnaíba, implicará o remanejamento de aproximadamente quinhentos e cinquenta e seis

\footnotetext{
${ }^{4}$ Spink (2010) considera como mapa tabela onde as colunas são definidas tematicamente pelo roteiro da entrevista ou pelas categorias indicadas pelo problema e objetivos da pesquisa e as linhas são indicadas por cada unidade analisada.
} 
famílias piauienses e maranhenses, sendo uma parte delas residente das áreas urbanas da Comunidade Riacho dos Negros, situada em Palmeirais (PI).

Dentre os diversos impactos causados pelo empreendimento, os mais graves serão o deslocamento compulsório da população da área e as diversas alterações nos meios físico, biótico e antrópico ou socioeconômico. Durante a audiência pública realizada para a exposição desses impactos, a população manifestou-se contra a instalação do empreendimento, considerando que o empreendimento não Ihes trará nenhum benefício. Contudo, os argumentos dos moradores não foram levados em consideração, assentado num entendimento de audiência pública no licenciamento ambiental como de natureza informava e não deliberativa, o que esvazia o sentido da audiência pública, um instrumento de papel importante em uma sociedade democrática, previsto pela Constituição Federal de 1988.

Diante disso, o Ministério Público Federal ajuizou Ação Civil Pública - $n^{\circ}$ 2010.40.00.002411-9 (1 $1^{\text {a }}$ Vara Federal/PI) - com pedido de liminar para impedir os leilões das barragens do Projeto Parnaíba (Leilão A-5) da Empresa de Pesquisas Energéticas (EPE), com destaque aos AHEs de Castelhano (Processo no 02001.002984/2004-11), Cachoeira e Estreito, cujos leilões foram marcados para ocorrer em conjunto. A Ação Civil Pública solicita que sejam invalidados os processos de licenciamento ambiental das cinco barragens, diante dos "vícios insanáveis" apontados, e que os requeridos se abstenham de licenciar usinas hidrelétricas no rio Parnaíba ou de iniciar qualquer atividade relativa à construção de empreendimentos dessa espécie sem contemplar, analisar e solucionar todos os aspectos referidos na ação e nos pareceres e laudos técnicos constantes no Inquérito Civil Público.

Porém, antes da data prevista para o leilão, o juiz da $2^{\text {a }}$ Vara da Justiça Federal do Piauí responsável indeferiu o pedido de liminar do MPF e, assim, permitiu que o leilão pudesse transcorrer.

O leilão não ocorreu, não para proteger as populações locais, mas por decisão dos empresários que não consideraram os empreendimentos viáveis economicamente. A última tentativa de leilão, em dezembro de 2012, fracassou, já que não houve nenhuma empresa investidora interessada no projeto sob a alegação 
de as condicionantes ambientais e socioculturais terem tornado o projeto inviável economicamente.

\subsection{A comunidade atingida e as violações de direitos humanos}

A comunidade de Riacho dos Negros será uma das atingidas com a construção da barragem. Segundo dados de um censo realizado no ano de 2012 pela Associação de Moradores, há na comunidade cerca de duzentos e sessenta imóveis, onde residem oitocentos e quarenta e um moradores. Dentre as localidades a ser inundadas na área, pode-se citar: Brejinho, Castelhano, Riachinho, Vitória, Cabeceira, Morros, São Joaquim, Fazendinha, Coxo - um assentamento do MST e Matinha. Assim, os moradores sofrerão deslocamento compulsório e reassentamento em terras mais distantes e os seus conhecimentos tradicionais associados à biodiversidade que gozam de proteção legal serão desfuncionalizados.

Em visita a Riacho dos Negros, através de observação, de conversas informais e entrevistas com moradores, foi possível identificar diversos conhecimentos relacionados à maneira de lidar com a terra e os recursos naturais, além de identidade cultural e vínculo afetivo, sentimento de pertencimento àquela região.

A maior parte da população possui apenas um pequeno lote de terra e vive da agricultura tradicional, em terras arrendadas, dos programas de transferência de renda do governo federal e/ou da aposentadoria rural. Há preferência por terras próximas à margem do rio Parnaíba, no trecho conhecido localmente como "Rio Velho", onde plantam melancia, arroz, feijão e milho, em conjunto com familiares.

Um dos conhecimentos tradicionais, transmitidos de geração em geração, que foi identificado é a prática da "pousio" da terra, ou seja, o lote de terra é dividido em três partes, entre as quais o agricultor alterna a cada cinco anos, em média. Além disso, eles não desmatam as margens do rio devido à preocupação em evitar o assoreamento. Práticas como queimadas para limpar o terreno das plantações também acontecem, mas as próprias características geográficas da região: o rio, que se divide em dois braços e o riacho que dá nome à comunidade cercam a área de cultivo e não permitem que o fogo se alastre. Poucas pessoas criam gado na 
região - estima-se que o maior criador tenha um rebanho de cerca de cem cabeças -, com predomínio dos pequenos criadores. Muitos criam galinha e pescam no rio, além de manterem um criatório de peixes na comunidade.

Como há grande quantidade de capivaras na região, que atacam as plantações e causam prejuízos, muitas vezes os agricultores precisam montar armadilhas para mantê-las afastadas e para manter o equilíbrio na quantidade de animais. Para isso, também há um conhecimento tradicional: a técnica da construção de "fojos", buracos disfarçados para a captura do animal, o que afugenta o restante do grupo. Algumas pessoas dominam ainda a técnica de produção de cestos artesanais, utilizando como matéria-prima a fibra de uma planta muito comum na região, conhecida popularmente como "unha-de-gato".

Além disso, podem ser observados diversos indícios de que Riacho dos Negros se trata de uma comunidade remanescente de quilombos, a começar pelo próprio nome. Sabe-se que a comunidade tem origem em uma grande fazenda, que demandava grande número de trabalhadores. Considerando o contexto de cerca de dois séculos atrás, tudo indica que esses se tratavam de escravos, antepassados dos atuais moradores da região. Os traços fenotípicos da população e características culturais como a tradicional dança do "tambor de crioula", praticada em terreiros e a própria influência do candomblé também podem ser apontados como herança negra.

Assim, levando em consideração os argumentos apresentados, pode-se entender Riacho dos Negros como comunidade tradicional e quilombola, ainda que em processo de autoidentificação. Esse reconhecimento implica que além dos direitos constitucionais válidos para qualquer cidadão brasileiro, a comunidade conta com uma série de dispositivos de proteção específicos que não estão sendo cumpridos, dentre os quais se podem citar: 0 artigo 68 do Ato das Disposições Constitucionais Transitórias, a Instrução Normativa no 57 do INCRA, a Convenção no 169 da Organização Internacional do Trabalho e os Decretos no 4.887/2003 e 5.051/2004 da Presidência da República.

$\mathrm{O}$ art. 68 do ADCT garante aos remanescentes dos quilombos o reconhecimento da propriedade definitiva das terras por eles ocupadas, cuja emissão dos títulos é de obrigação do Estado. O decreto no 4.887/2003 regulamenta 
o art. 68 do ADCT, estabelecendo o procedimento de identificação, reconhecimento, delimitação e titulação das terras ocupadas pelos remanescentes dos quilombos procedimento este regulamentado pela Instrução Normativa ํo 57 do INCRA.

A Convenção o 169 da OIT, por sua vez, em seu artigo 6º, define como obrigação dos governos: "consultar os povos interessados, mediante procedimentos apropriados e, particularmente, através de suas instituições representativas, cada vez que sejam previstas medidas legislativas ou administrativas suscetíveis de afetálos diretamente". Por fim, o decreto n 5.051/2004 promulga a Convenção $n^{\circ} 169$ da OIT.

Além de colocar em risco o modo de vida tradicional da população local, a construção da barragem de Castelhano também representa ameaça à fauna e flora locais. A vegetação da área é classificada como ecótona, extremamente rica e exuberante, com espécies de árvores típicas de diferentes biomas, como Caatinga, Cerrado, Mata de Cocais e até mesmo da Mata Atlântica, além de algumas exclusivas daquele trecho. O prejuízo causado pela inundação será inestimável, com a perda de milhares de espécies que sequer foram catalogadas e poderiam ser utilizadas inclusive na indústria farmacêutica ou de cosméticos, por exemplo.

Existem na região de Riacho dos Negros riquezas arqueológicas, como as pinturas rupestres do Morro do Letreiro, que nunca foram objeto de estudo e sequer foram catalogadas. Por ser uma área alta, o morro não ficaria submerso com o represamento do rio, mas todas as vias de acesso o seriam, o que significaria a impossibilidade de locomoção ao local e a perda de todo esse material de estudo. Isso levou o IPHAN a recomendar a prospecção arqueológica da área antes da inundação no parecer solicitado pelo órgão licenciador na análise para emissão da Licença Prévia.

Ciente do panorama descrito, o Instituto Brasileiro do Meio Ambiente e dos Recursos Naturais Renováveis - IBAMA concedeu a Licença Prévia relativa ao Aproveitamento Hidrelétrico Castelhano em novembro de 2011, porém atrelada a uma série de condicionantes, ou seja, as exigências a serem cumpridas pela empresa no intuito de minimizar os impactos ambientais e os danos para as comunidades atingidas. As condicionantes teriam encarecido consideravelmente 0 
projeto, o que supostamente fez com que as empresas perdessem o interesse em investir, devido à previsão mais tímida de retorno financeiro.

Um aspecto relevante a ser citado é que a comunidade foi ouvida e várias demandas da população foram incorporadas como condicionantes, que exige, por exemplo, o detalhamento do Plano Básico Ambiental (PBA), a identificação de espécies da fauna e flora e a prospecção e salvamento arqueológico na região. Estabelece a Licença Prévia no 422/2011:

Em relação aos entes parceiros: IPHAN - (i) implementar os programas ambientais $\mathrm{e}$ as medidas necessárias para prospecção e salvamento arqueológico, os quais deverão estar em conformidade com a Portaria IPHAN no 2030, de 17/12/2002; (ii) identificar e inventariar os bens arqueológicos, históricos e culturais empreendidos pelo empreendimento e propor medidas mitigadoras e/ou compensatórias (...); No âmbito do PBA e do Cadastro Socioecônomico: Apresentar levantamento censitário de todos os públicos que desenvolvam atividades econômicas na ADA do empreendimento ou que utilizem de seus recursos naturais, incluindo agregados, posseiros e vazanteiros, residentes ou não na ADA. O empreendedor deverá promover o reassentamento dessa população e garantir o aporte técnico e financeiro necessários para a recomposição de suas atividades em condições iguais ou melhores que as atuais (...); As atividades incompatíveis com os usos do reservatório e/ou cujo desenvolvimento em outras áreas seja tecnicamente inviável, assim como aquelas não localizadas na ADA, mas que dela dependam para manutenção de sua viabilidade econômica, deverão ser indenizadas ou substituídas por alternativas de geração de renda. Estas deverão ocorrer apenas após discussão prévia e aprovação pelos segmentos interferidos (...); Adotar, durante o processo de relocação da população interferida, medidas que visem preservar as relações de vizinhança e os vínculos sociais e familiares. (LICENÇA PRÉVIA № 422, 2011, p. 3-5).

Por fim, tendo discorrido sobre as implicações da construção da Barragem de Castelhano para o meio ambiente e para as comunidades tradicionais da região, além de apresentado os aspectos que permitem a identificação de seu modo de vida na relação com a biodiversidade local, a próxima seção propõe-se a analisar o caso sob a perspectiva das teorias de relevantes autores da sociologia e antropologia jurídicas. 


\subsection{0 conflito e a busca de solução não-violenta}

Em sua obra, Norbert Rouland (2004) tem o objetivo de fazer um manual dos direitos das minorias e dos povos autóctones. Para o autor, uma democracia, tal qual a definida pelo Estado brasileiro, supõe que todos os indivíduos sejam representados e representáveis.

A democracia apareceu quando os indivíduos puderam basear suas reivindicações na existência e na ação de poderosos atores sociais organizados de maneira autônoma. Contudo, ela é fraca ou inexistente quando o governo a estabelece ou controla (ROULAND, 2004, p.11).

Ao permitir que o leilão das barragens acontecesse, a $2^{\text {a }}$ Vara da Justiça Federal do Piauí vulnerabilizou os direitos das populações tradicionais residentes na região e ampliou o direito ao desenvolvimento. Embora o leilão não seja, de fato, etapa autorizadora do início da obra, que, na verdade, apenas se configura com a Licença de instalação, é uma etapa importante a ser autorizada sem as correções exigidas nas condicionantes da Licença Prévia.

É possível levantar outro aspecto: democracia está ligada ao desenvolvimento econômico? Rouland (2004) considera que, após a Segunda Guerra Mundial, propagou-se a ideia de que o desenvolvimento econômico tornaria a sociedade homogênea, diminuindo a pluralidade, e traria inevitavelmente o bem às pessoas. É sobre o pretexto do desenvolvimento que os defensores da barragem tentam levar adiante a sua construção. Não se pode, entretanto, esquecer que foi sobre tal pretexto do desenvolvimento que diversos regimes tentaram acabar com os direitos das minorias e autóctones e varrer as particularidades dos povos. Os exemplos vão desde a era das navegações, quando a Igreja Católica e o governo de Portugal, por meio dos jesuítas, tentavam acabar com a cultura dos índios, fazendo-os se adaptarem aos dogmas da religião católica, até os dias atuais, com os conflitos étnicos ao redor do globo. Portanto, para o já citado autor:

O desenvolvimento econômico não foi, para eles [os autóctones], sinônimo de progresso, salvo a contrario. Em muitas regiões do mundo, as "necessidades" desse desenvolvimento são a causa de sua devastação. E, nos países desenvolvidos, a promoção dos direitos dos autóctones é, em grande parte, o fruto dos combates jurídicos e políticos № 40| p. 70-89 |AGO - OUT 2013 
conduzidos contra projetos de desenvolvimento sobre os quais eles não teriam nenhum controle. (ROULAND, 2004, p. 21).

É na luta contra os projetos de desenvolvimento que os autóctones e as minorias buscam o reconhecimento de seus direitos. Mas ao mesmo tempo as populações citadas demandam políticas e/ou leis que garantam os seus modos de vida. É possível então afirmar que buscam desenvolvimento, evidentemente, como conceito com sentido diferente do referido anteriormente, o que atesta a pluralidade do conceito e que um sistema jurídico democrático que reconheça e respeite o direito de todos os seus nacionais e outros que por aqui transitem precisa considerar a pluralidade também da categoria desenvolvimento. E que as expressões contra os projetos de desenvolvimento tratam-se de denúncia de atuação monista do Estado.

Bronislaw Malinowski (2003) considera que os estudos a respeito dos povos autóctones têm o defeito de diminuir a importância do direito de povos tidos como primitivos e de observá-los a partir de um olhar etnocêntrico. $O$ desinteresse pela lei primitiva, por parte dos antropólogos anteriores ao citado autor, pode ser comparado analogamente ao das entidades governamentais em relação aos costumes e tradições da comunidade de Riacho dos Negros. Dissipar a comunidade e removê-la do seu lugar de origem pode causar impactos não só do ponto de vista econômico, mas cultural, à medida que a comunidade vai perdendo marcas de sua identidade ao mudar seu local de estabelecimento e perder o contato com a biodiversidade que conhece. A maneira como os empresários e entidades do governo observam comunidades tradicionais como Riacho dos Negros demonstra consonância com a perspectiva etnocêntrica.

Assim, a indiferença pelo conhecimento sobre os costumes e tradições das populações tradicionais leva a impasses no direito. Quanto mais o grupo dominador ignora as reivindicações do grupo minoritário, mais complexa fica a questão acerca de uma universalidade do direito. As práticas de efetivação e aplicação das legislações, em forma de políticas públicas e de decisão judicial, desconsideram o papel das minorias e dos autóctones na sociedade e o resultado são as atuais violações aos direitos humanos, ocorridas tanto em escala global, quanto no caso estudado. 
Pode-se relacionar, ainda, o caso estudado a Bourdieu (1998), no que diz respeito à sua teoria de campos e à abordagem sobre violência simbólica. Para o autor, o campo é o espaço em que são travadas disputas por objetos e interesses próprios dos indivíduos. Assim, existem diversos campos, como, por exemplo, o do direito, no qual se trava a disputa pelo monopólio do direito de dizer o direito. Podese comparar o plano de ação social do caso estudado a um campo, em que os empresários e a população local são agentes que travam uma disputa pela posse da terra e que o Poder Judiciário, na decisão proferida e o Estado na emissão da Licença fortaleceram o lado dos empresários, consequentemente, vulnerabilizando o outro lado do campo. Além disso, é no contexto do campo que ocorre a chamada violência simbólica, processo pelo qual a classe dominante se impõe sobre os dominados, por meio de práticas que induzem o indivíduo a seguir o que é estabelecido por aquela classe.

A violência simbólica ocorre em diferentes ambientes, como nas instituições governamentais, nas escolas, e até mesmo no sistema do direito: as autoridades jurídicas utilizam uma violência simbólica ao buscar legitimidade para os seus atos de violência na lei. No caso estudado, a tentativa de desapropriação dos habitantes de Riacho dos Negros, em vista dos planos do Estado de construir uma barragem, é uma forma de violência simbólica, na medida em que a população local se encontraria obrigada a obedecer a uma decisão que, ao invés de trazer benefícios, prejudicaria a vida de toda a comunidade. Tal fato traz à tona o questionamento acerca das implicações sociais do direito nas decisões judiciais e do poder executivo. Percebe-se, então, que Bourdieu (1998), em sua teoria, enfatiza o papel dos agentes, que participam das disputas de objetos e interesses.

Ulrich Beck (1997), por sua vez, em sua teoria da sociedade de risco, toma como foco as estruturas ao propor a análise da sociedade sob uma perspectiva diferente. Então, Beck apresenta o conceito de "modernização reflexiva", que se refere à possibilidade de destruição criativa para a era industrial, cujas certezas seriam substituídas por novas certezas, mais temporárias, falíveis e sujeitas a serem contestadas pelo risco. Desse modo, o autor introduz a ideia de sociedade de risco, que consistiria na atual fase do desenvolvimento da sociedade moderna, em que os 
riscos sociais, políticos, econômicos e individuais tendem a escapar do controle das instituições.

Toda a preocupação no que diz respeito às consequências da construção da Barragem de Castelhano e todos os riscos para a sociedade, para a biodiversidade da região e inclusive para o direito - tendo em vista que a violação aos direitos das comunidades tradicionais poderia gerar questionamentos quanto à eficácia de todo o sistema - permitem a identificação da sociedade atual como referente ao segundo estágio da sociedade de risco. Indício disso é o fato de que os perigos dominam o debate público e os conflitos de interesse entre público e privado. Além disso, o risco passa a ser visto como permanente - ainda que não seja regra -, exigindo precauções e o monitoramento contínuo como forma de enfrentar os riscos.

Nesse contexto, isso pode ser verificado, no âmbito do Direito Ambiental, diante da necessidade de estabelecer mecanismos capazes de permitir a ponderação dos riscos da implantação de um grande empreendimento em certa área, por exemplo. Assim, surgiu a exigência de Estudos de Impacto Ambiental (EIA), da elaboração de Relatórios de Impacto Ambiental (RIMA), Projeto Básico Ambiental (PBA) antes do licenciamento da obra. Após a análise dos dados coletados, avalia-se se o projeto é viável ou os riscos potenciais são excessivamente elevados e, por meio do IBAMA, são definidos se possíveis ou não de serem implantados através de licenças ambientais ou estabelece condicionantes a cujo cumprimento está atrelada a liberação de licenças. Foi esse o caso da barragem de Castelhano, como já explicado, que precisa cumprir uma série de condicionantes, que incorporam reivindicações da população atingida e podem ser vistas como uma tentativa de gerenciar ou de lidar com o risco.

Entretanto, ainda há uma discursividade que se filia ao primeiro estágio da sociedade de risco de Beck (1997), a de risco residual, em que o risco não é tido como problema e quando aparece, é visto como infortúnio, apenas resíduo de determinada ação ou tomada de decisão. As consequências negativas de uma grande obra como Castelhano são subestimadas e a atuação é fundada na alegada supremacia do interesse público como suficiente para justificar a obra.

No entanto, pode-se perceber que a referida barragem, bem como as outras quatro previstas para o curso do rio Parnaíba são investimentos públicos, com № 40| p. 70-89 |AGO - OUT 2013 
recursos federais para atender à demanda por energia elétrica e ao clamor por infraestrutura para empresas privadas. A população piauiense não seria beneficiada diretamente com a melhora na qualidade da energia elétrica, já que a produção relativa às novas barragens se destinaria a grandes empresas atraídas para o estado à custa de subsídios, isenção fiscal e complacência na distribuição dos danos ambientais. Assim, as populações tradicionais seriam as maiores prejudicadas, por herdarem a maior parcela nessa distribuição dos danos a que se refere Beck (1997), enquanto as grandes empresas colhem os frutos dessas obras de interesse privado disfarçado de interesse público.

O que fazer diante do exposto? Denunciar a parcialidade de interesses na gestão pública? Evidentemente a denúncia é importante, mas apenas denunciar não orienta ações futuras. Não se pode negar a existência do direito ao desenvolvimento, a importância e necessidade do princípio da supremacia do interesse público.

$\mathrm{Na}$ discussão do que fazer, de como lidar com direitos plurais, diversidade e democracia, Beck propõe o modelo da "mesa-redonda" como forma de lidar com essa tensão:

Qualquer um que não deseje mais aceitar o "destino" da produção de efeitos colaterais e riscos, e assim deseje forçar a perda de legitimação associada ao desenvolvimento tecnoindustrial, deve considerar como a "nova ambivalência" pode se tornar aceitável e capaz de formar um consenso. A resposta são as instituições de mediação inter-sistêmicas. Estas existem em uma forma rudimentar nos vários modelos da "mesaredonda" ou nas comissões de investigação, éticas ou de risco (BECK, 1997, p.42).

Outro aspecto que merece ser analisado é o fato de que a audiência pública entre os responsáveis pelo empreendimento de Castelhano e os moradores das comunidades atingidas teve caráter meramente informativo, em que foram expostas algumas características do projeto e observações a respeito do EIA-RIMA, ou seja, não passa de um simulacro de participação. Infelizmente, este tem sido o "modelo" de audiência pública adotado no Brasil nos casos de licenciamento ambiental, o que claramente contraria a Convenção nำ169 da OIT, da qual o país é signatário, que prevê a realização de consulta prévia como forma de permitir que as comunidades № 40|p. 70-89 | AGO - OUT 2013 
tradicionais participem do processo de tomada de decisões em casos de medidas legislativas ou administrativas suscetíveis de afetá-los diretamente e não apenas isso, trata-se de violação do princípio democrático constitucional brasileiro.

Pode-se estabelecer relação entre a consulta prévia estabelecida pela OIT e o princípio democrático da $\mathrm{CF} / 88$ que deve orientar a realização de audiências públicas com a Teoria da Ação Comunicativa de Jürgen Habermas (2003). Segundo o pensamento do autor, a razão comunicativa tem o fim de alcançar o entendimento e a compreensão mútua. Assim, é exigido que aquele que faz uso da linguagem assuma uma atitude performativa de igualdade, que garante a validade do discurso. A teoria do Direito e da democracia contemporânea defendida por Habermas tem como pressuposto a força socialmente integradora da fundamentação racional, o que se reflete nos processos não-violentos de se alcançar o entendimento. Dessa forma, fica evidente a necessidade de diálogo, de tentativa de entendimento e acordo entre as duas partes, sendo as audiências públicas uma oportunidade para tal, desde que se efetivem como lugar de discussão, convencimento e deliberação.

Faz parte do pressuposto de processos não-violentos para alcançar o entendimento a concepção do direito como um sistema que deve conter os direitos que os cidadãos precisam conceder um ao outro se constituíram o seu viver conjunto regulado por intermédio do Direito positivo, que atribua um igual peso tanto à autonomia privada quanto à pública do cidadão, que garanta os direitos basilares que os cidadãos devem reciprocamente se reconhecer, em que a autonomia privada avança até o limite em que o sujeito jurídico não tenha que prestar contas aos outros ou fornecer razões publicamente aceitáveis para os seus planos de ação. Além disso, é necessário que os submetidos ao Direito enquanto seus destinatários possam ao mesmo tempo ser compreendidos também como os autores daquele e que a coerção jurídica não destrua os motivos racionais de obediência ao Direito.

Para atender aos pressupostos acima no caso em estudo, os atingidos precisam ser tratados com igual respeito e consideração, os seus direitos precisam ser considerados e garantidos no processo de implantação. Assim, a saída sem violência para o conflito deve ser alcançada em conjunto com os próprios atingidos/interessados. 
Retomando a ideia de "risco", é possível identificar uma ligação entre o conceito de sociedade de risco de Beck (1997) e o pensamento de Habermas, perfeitamente aplicável ao caso sob análise. Habermas (2003) defende que a ação comunicativa pode controlar o risco de dissenso construído em seu interior mediante o incremento do próprio risco, ou seja, tornando o risco permanente. Nesse sentido, o direito ambiental, uma área em que os riscos e ameaças estão sempre presentes, esse raciocínio é extremamente válido.

Ainda na concepção de risco, é válido destacar o entendimento de Luhmann (1983), que adota a forma de lidar com o risco tomando-o como certo e de origens diversas, conhecidas e desconhecidas. O referido autor considera que o ser humano vive em um mundo com uma multiplicidade de possíveis experiências e ações confrontado com o seu limitado potencial de percepção, assimilação e ação atual e consciente e que cada experiência concreta apresenta um conteúdo evidente que remete a outras possibilidades que são ao mesmo tempo complexas e contingentes por sempre haver mais possibilidades do que se pode realizar. Isso conduz a uma seleção forçada e, em razão de as possibilidades apontadas sempre poderem ser diferentes das esperadas, verifica-se o perigo permanente de desapontamento e a necessidade de assumir riscos. Assim, a formação de sistemas para estabilizar os desapontamentos diz respeito ao desenvolvimento de estruturas de assimilação da experiência para absorver e controlar o duplo problema da complexidade e da contingência com atuação também complexa e contingente, o que leva a concluir que ao invés de ter o risco como exceção, como infortúnio, o mesmo precisa ser tomado como certo, mas numa certeza contingente.

Por fim, é válido observar que a elaboração do EIA-RIMA é uma modalidade de planejamento, ou seja, um procedimento para lidar com o risco que transcende os limites do direito. Nota-se a incorporação da perspectiva da administração, caracterizada por esse viés de previsão, avaliação da viabilidade, das possibilidades de êxito do empreendimento, por exemplo. Esse aspecto pode ser relacionado à teoria sistêmica de NiklasLuhmann (1983) segundo a qual cada sociedade consiste em um sistema social, um ambiente complexo e contingente, sendo que os sistemas tem origem na diferenciação funcional. Assim, cada sistema seria autopoiético, ou seja, produtor de si próprio, com a oportunidade de comunicação entre os sistemas. 
E é, exatamente, a oportunidade de comunicação intersistêmica que pode enfrentar o risco.

\section{CONSIDERAÇÕES FINAIS}

Ao longo deste trabalho, apresentou-se o caso da barragem de Castelhano, a partir da descrição e das implicações do empreendimento para as comunidades tradicionais e para a biodiversidade local. Então, procurou-se abordar alguns aspectos relevantes do caso relacionando-os a teorias tradicionais $\mathrm{e}$ contemporâneas da sociologia e antropologia jurídicas.

Assim, pretendeu-se avaliar os riscos da construção da barragem de Castelhano para a sociedade, para a biodiversidade da região e inclusive para 0 direito, permitindo a identificação da sociedade atual como referente ao segundo estágio da sociedade de risco de que trata Ulrich Beck (1997). É importante destacar ainda que se intentou expor elementos que corroboram a tese de falseamento do caráter público do empreendimento, além das violações sistemáticas aos direitos das comunidades tradicionais atingidas.

Diante disso, pôde-se constatar que são de fundamental importância os processos não-violentos de se alcançar o entendimento a que se refere Jürgen Habermas (2003) na sua teoria do Direito e da democracia contemporânea. Em outras palavras, é indispensável encontrar mecanismos eficazes para se lidar com o risco, sendo o diálogo e a comunicação intersistêmica, com a garantia de inclusão de todas as pessoas interessadas e/ou atingidas, formas de buscar o entendimento entre as partes.

\section{REFERÊNCIAS}

BECK, Ulrich. In: GIDDENS, A. Modernização reflexiva. Política, tradição e estética na ordem social moderna, São Paulo: UNESP, 1997.

BOURDIEU, Pierre. O Poder Simbólico. Rio de Janeiro :Bertrande Brasil, 1998.

BRASIL. Ministério Público Federal. Ação Civil Pública (Processo oㅡ 2129573.2011.4.01.4000). Procurador: Marco Aurélio Adão. Teresina, 17 de outubro de 
2011. Disponível em: <http://www.prpi.mpf.gov.br/www/arquivos/acp/ACP-Aneel-rioparnaiba.pdf>. Acesso em: 14 dez. 2012.

DWORKIN, Ronald. Levando os direitos a sério. São Paulo: Martins Fontes. 2002. . O Império do Direito. São Paulo: Martins Fontes, 2007.

GOLDEMBERG, Mirian. A arte de pesquisar - como fazer pesquisa qualitativa em ciências sociais. Rio de Janeiro-São Paulo; Editora Record, 2004.

HABERMAS, Jürgen. Direito e Democracia - entre facticidade e validade, vol. I. $2^{\mathrm{a}}$ ed. Rio de Janeiro: Tempo Brasileiro, 2003.

A Lógica das Ciências Sociais. Petropolis: Vozes, 2009.

LUHMANN, Niklas. Sociologia do Direito I. Rio de Janeiro: Tempo Brasileiro, 1983.

MALINOWSKI, Bronislaw. Crime e costume na sociedade selvagem. Brasília: Editora Universidade de Brasília; São Paulo: Imprensa oficial do estado, 2003.

ROULAND, Norbert (org.). Direito das minorias e dos povos autóctones. Brasília: Editora Universidade de Brasília, 2004.

SPINK, Mary Jane. Linguagem e Produção de sentidos no cotidiano. Centro Edelstein de Pesquisas Sociais : Rio de Janeiro, 2010.

WEBER, Florence. A entrevista, a pesquisa e o íntimo, ou: por que censurar seu diário de campo? In: Rev. Horizontes Antropológicos, Porto Alegre, ano 15, n. 32, p. 157-170, jul./dez. 2009. 